\title{
The Components Of A Successful CEO Apology
}

Krista M. Hill, (Ph.D. Candidate), Northeastern University, USA David P. Boyd, D.Phil., Northeastern University, USA

\begin{abstract}
Although most research suggests that apologies are associated with positive outcomes, the relationship can be equivocal. An apology's effectiveness is highly dependent on whether certain components are present. The current study investigates the effectiveness of various apology components proposed by Boyd (2011). Twenty-five CEO apologies were coded for seven components: revelation, recognition, responsiveness, responsibility, remorse, restitution, and reform. These apologies were then shown to 151 participants who rated their willingness to forgive and trust the apologizers. All components were significant except for responsibility.
\end{abstract}

Keywords: CEO Apology; CEO Forgiveness; Apology Components

\section{INTRODUCTION}

$\mathrm{n}$ recent years apologies have become increasingly prevalent in public life. With so many CEOs and e companies seeking the public's forgiveness, an important empirical question emerges: "What makes an apology effective?" Since such public apologies entail a wider audience than simple interpersonal dynamics, how can these transgressors know whether their words of penance were accepted? The current study addresses this issue. Using real CEO apologies, we assess the relationship among various apology components, forgiveness, and trust.

\section{Are Apologies Effective in Producing Positive Outcomes?}

A company's public image is important and highly dependent on media coverage and public opinion. When missteps occur, companies often proffer apologies in an effort to repair their reputations (Hareli, Shomrat, \& Biger, 2005). The question is whether behaviors such as apologizing achieve the desired effect.

Characteristically, the literature has found that apologies are associated with many positive outcomes. Fehr, Gelfand, and Nag's (2010) meta-analysis of the situational and dispositional correlates of forgiveness found an overall effect size of $\mathrm{r}=.42$ for the apology-forgiveness relationship. In addition, apologies have been associated with the offended party's positive emotions and positive perceptions toward the transgressor (DeCremer, van Dijk, \& Pillutla, 2010; Xie \& Peng, 2009). For example, DeCremer, van Dijk, and Pillutla (2010) presented participants unfair offers in an ultimatum game. Some participants were in an apology condition in which they read, "I'm sorry about the offer that I just made. I will try to do better next time." The remainder was in a denial condition where they read, "I do not feel responsible for the offer that I made and its possible consequences. I deny bad intentions from my side." Participants in the apology condition rated the transgressors as more trustworthy than those in the denial condition.

Additionally, research has shown that apologies are associated with increased compliance (Goei, Roberto, Meyer, \& Carlyle, 2007), satisfaction (Howley, 2009), purchase intentions (Liao, 2007), and affiliative actions such as investing in a company, recommending a company, and requesting further information about a company (Lyon \& Cameron, 2004). 
Despite showing significant relationships between apologies and positive outcomes, these studies demonstrate that the connection is not perfect. For a variety of reasons, some apologies are more effective than others (e.g., DeCremer et al., 2010; Eaton, Struthers, Shomrony, \& Santelli, 2007; Zechmeister, Garcia, Romero, Vas, 2004). Researchers have suggested that a primary reason for the imperfect correlation is the variant verbal components that apologies contain (Lazare, 2005). The presence of these components affects whether the outcomes will be positive. This leaves the question, "What are these components?" Extrapolating from previous research, Boyd (2011) proposed a comprehensive model of verbal actions that might be implicated in the etiology of effective apologies. We discuss the model below.

\section{The Components of an Effective Apology}

Boyd's (2011) sequential stepwise model delineates seven steps to forgiveness. The original schematic of seven R's is depicted in Figure 1. The model begins with revelation, which refers to an apologizer's announcement of the violation and also entails an explanation of its context. Conversely, deflective stratagems such as dissociation and diminution are flawed attempts to diminish the gravity of the act. Dissociation is a delusive effort to apologize for an error without acknowledging personal proximity to the situation. Diminution is another self-serving approach that seeks to dilute the injurious impact of a transgressor's act.

\begin{tabular}{lllllll} 
Revelation & Recognition & Responsiveness & Responsibility & Remorse & Restitution & Reform \\
\hline Explanation & Empathy & Timeliness & Internal Attribution & Guilt & Compensation Change \\
Evasion Dissociation & & & & & & \\
& Estrangement & Tardiness & External Attributionn & Guile & Abrogation & Complacency
\end{tabular}

\section{Figure 1: Boyd's (2011) Apology Component Model}

Recognition involves some demonstrable sign of empathy for those impacted by the lapse. Apologizers recognize the harm they have brought upon others and express this understanding to the offended party. For example, an apologizer might say, "I understand that you are upset."

Responsiveness considers whether an error is acknowledged in timely fashion. If apologizers are delinquent in proffering an apology, they lose control of information flow and thereby encourage offended parties to form unabated impressions about the occurrence. On the other hand, by speaking too hastily, apologizers might be perceived as disingenuous because they have not taken full stock of the transgression's impact.

Apologizers demonstrate responsibility by "owning" their mistake without blaming the transgression on an outside source. For example, an apologizer may say, "It was my fault." If instead they try to ascribe causality to events beyond the self, they will appear evasive and be held even more accountable for failure. In an effort to eschew responsibility, these actors might resort to dispersion by extending the panoply of perpetrators. They might also engage in displacement by apologizing for the wrong thing, usually an error of lesser magnitude.

Remorse as used here suggests some sense of guilt and expressed shame. It is more profound and visceral than regret because its scope supersedes sorrowful reaction to an act; actors feel badly about themselves for engaging in the behavior and subject themselves to psychic penalty.

The final two categories are framed in terms of action orientation. Compensation, whether reputational or monetary, is a tangible step to redress the lapse. It can carry both substantive and symbolic appeal. While such an offering cannot negate the original deed, it can confer a halo of restorative justice.

Reform is the final rubric and incorporates pre-emptive measures. Since reform is consequent to the misstep, it assures the public that any further proclivity for malfeasance is likely to be thwarted. It is of course imperative to show that reforms have been structurally implemented. Promises alone are insufficient to deter errant behavior. 
The model rested on the assumption that the more elements present, the more powerful the palliation of a violator's misdeed. However, the previous study included no attempt to measure whether all steps are conducive to forgiveness, nor did it indicate whether certain post-apology actions might be more efficacious than others. In an attempt to address these issues, the present paper specifically examines the relative influence of construct components.

\section{THE CURRENT STUDY}

The current study tests Boyd's (2011) model by utilizing real public apologies made by CEOs. The CEO apologies were coded for the various components identified by Boyd (2011). They were then shown to judges who rated the extent to which they would forgive and trust the apologizing company. The relationship between the coded components and the judge-rated outcomes was investigated.

\section{METHODS}

\section{Stimuli Creation}

An Internet search for CEO apology transcripts yielded 83 results. From this sample we chose 25 apologies at random. These apologies emanate from companies that vary by sector and size. The transgressions committed by the companies also varied greatly. See Table 1 for the list of companies and their transgressions.

The transcript of each apology was read and coded by five individuals (the two authors and three research assistants). A five point scale rated the extent to which the following seven components were present: revelation, recognition, responsiveness, responsibility, remorse, restitution, and reform. A "0" was given if the component was absent while a " 5 " was given if the component was present, detailed, and obvious. We examined the reliability of the coders' ratings. The Cronbach's alpha coefficients for the components were $.90, .78, .90, .88, .75, .94$, and .90 , respectively. These reliability scores suggest high inter-rater reliability. Thus, we were able to aggregate the five coders' ratings resulting in a composite score for each component of each apology.

\section{Participants}

Participants were students enrolled at a large urban university. 151 subjects (101 women and 50 men) completed the study. Their mean age was 19.87 , and they were primarily white undergraduate students. Participants were offered extra credit for completing the survey.

\section{Measures}

Participants Ratings of the Transgressions. Because the nature of a transgression can affect the likelihood of forgiveness (Fincham, Jackson, \& Beach, 2005), we asked participants on a five point scale how severe they believed the transgression was. A 1 represented low severity, while a 5 represented "incredibly severe".

Participants Ratings of the Apologies. After reading each apology, participants were asked to what extent they would (1) forgive the company and (2) trust the company. For each company both of these items were rated on seven point scales with a 1 representing "will definitely not forgive or trust" and a 7 representing "will definitely forgive or trust." The scores were then averaged across participants. We chose variables associated with the company as opposed to the CEO for two reasons: 1) forgiveness of the company is more important than forgiveness of the CEO because consumers are purchasing from the company and therefore must forgive the company and 2) in most cases the CEO is not the direct transgressor and is merely representing the transgressing entity.

\section{Procedures}

Participants completed the study online using www.qualtrics.com. After the consent process, a summary of the first transgression was presented and participants rated its severity. Next, the apology transcript for the transgression was presented. Along with the transcript, participants were told how many days it took the company to 
apologize for the lapse. Participants then rated their proclivity to forgive and trust the company. This process continued until all 25 apologies were viewed. The apologies were randomized.

\section{RESULTS}

\section{Transgression Severity}

Table 1 summarizes the mean severity scores for each of the apologies. As shown, participants reacted negatively to misdeeds that were horrific in nature such as Ray Brent Marsh's crematorium defilement as well as missteps such as Citibank's that threatened security. The racist behavior exhibited by Marshalls was also rated as severe. On the other hand, participants rated as less severe transgressions associated with inconvenience like KFC and JetBlue.

Table 1: Transgression Description and Mean Severity Scores for Apologizing Companies

\begin{tabular}{|c|c|c|}
\hline Company & Mean Severity & Transgression \\
\hline Citibank & 4.03 & Sent envelopes with customers' social security numbers on outside \\
\hline Ray Brent Marsh & 3.87 & $\begin{array}{l}\text { Left corpses on the property of his crematorium and Crematorium gave family } \\
\text { members cement dust as their ashes }\end{array}$ \\
\hline Marshalls & 3.76 & $\begin{array}{l}\text { Posted a store memo stating that workers could not accept linen returns from } \\
\text { black customers }\end{array}$ \\
\hline Starbucks & 3.73 & $\begin{array}{l}\text { Starbucks employees charged } 9 / 11 \text { rescue workers } \$ 130 \text { for water on the day of } \\
\text { the World Trade Center attack }\end{array}$ \\
\hline Barson Travel & 3.59 & Defrauded people of $\$ 800,000$ for vacations that they never got to take \\
\hline Dominos Pizza & 3.59 & Employees made a video in which health codes were violated \\
\hline Mattel & 3.56 & Sold lead-tainted toys \\
\hline Blackberry & 3.21 & Service outages \\
\hline Brown \& Williamson & 3.03 & Denied that smoking is harmful \\
\hline Taco-Bell & 3.01 & $\begin{array}{l}\text { Fired a store manager because she left during her shift to help a teenager } \\
\text { injured in a street fight }\end{array}$ \\
\hline Caldor & 2.99 & $\begin{array}{l}\text { Sent } 85 \text { newspapers a toys-and-games advertising supplement showing two } \\
\text { boys at a Scrabble board that spelled the word "RAPE." }\end{array}$ \\
\hline McDonalds & 2.98 & Mislabeled food as "vegetarian" \\
\hline Barneys & 2.97 & Displayed an inappropriate nativity scene in front window \\
\hline Netflix & 2.92 & Poor communication about price increase \\
\hline Facebook & 2.88 & Changed privacy settings without informing users \\
\hline Best Buy & 2.83 & High pressure sales tactics \\
\hline Chevron & 2.77 & $\begin{array}{l}\text { Pressured handicapped Boy Scouts to shut down their Christmas tree lot } \\
\text { because it blocked a Chevron sign }\end{array}$ \\
\hline Chrysler & 2.75 & $\begin{array}{l}\text { Disconnected the odometers on } 60,000 \text { cars before test-driving them and sold } \\
\text { these cars as "new" }\end{array}$ \\
\hline Groupon & 2.71 & Aired sensitive ad during Superbowl \\
\hline Disney & 2.61 & Ended program that offered discounts to special needs children \\
\hline Amazon & 2.48 & Deleted unauthorized Kindle books without informing users \\
\hline Kenneth Cole & 2.42 & Insensitive comment on Twitter \\
\hline JetBlue & 2.37 & Delayed and cancelled flights \\
\hline Wal-Mart & 2.36 & Labeled clothing "Made in USA" that was not \\
\hline KFC & 2.06 & Unable to meet customer demands for coupon redemption \\
\hline
\end{tabular}

\section{Mean Component Score}

The mean scores in Table 2 show how often each component was present in the CEO apologies. All components appear to be used to some extent. Responsibility received the highest mean rating suggesting that CEOs often attribute the transgression to an internal lapse rather than an external intervention. For example, Groupon's CEO, Andrew Mason, apologized for running an inappropriate ad by saying, "I personally take responsibility; although we worked with a professional ad agency, in the end, it was my decision to run the ads" (Mason, 2011). Here Mason is accepting blame instead of accusing the ad agency. 
Restitution received the lowest mean rating suggesting that CEOs seldom recompense for wrongdoing. Restitution may not occur simply because it is difficult to make amends for many of the transgressions committed in this sample. For instance, Citibank would be challenged to conceive appropriate compensation for its customers whose social security numbers were printed on the mailing envelopes. However, some companies could make provision for restitution. For example, KFC offered customers rain-checks on their free meals as well as free soda to make up for the franchises' failure to meet earlier demand.

\section{Component-Outcome Relationship}

The relationship between the components and apology outcomes was examined by correlating the mean component scores for each company with the (1) mean forgiveness score and the (2) mean trust score. Table 2 summarizes the results of this analysis. Revelation, recognition, responsiveness, remorse, restitution, and reform all appear to be important components that predict forgiveness and trust. Responsibility appears to be the only component that does not predict the outcomes.

Table 2: Zero-Order Correlations between Apology Components and Judge Rated-Outcomes

\begin{tabular}{|c|c|c|c|c|c|}
\hline \multirow[b]{2}{*}{ Component } & \multirow[b]{2}{*}{ Mean } & \multirow[b]{2}{*}{ Forgive } & \multirow[b]{2}{*}{ Trust } & \multicolumn{2}{|c|}{ Controlling for Severity } \\
\hline & & & & Forgive & Trust \\
\hline Revelation & 3.13 & $.68 * *$ & $.60 * *$ & $.74 * *$ & $.66^{* *}$ \\
\hline Recognition & 2.31 & $.38^{+}$ & $.35^{+}$ & $.42 *$ & $.40^{+}$ \\
\hline Responsiveness & 2.74 & $.56 * *$ & $.56 * *$ & $.49 *$ & $.48 *$ \\
\hline Responsibility & 3.31 & .09 & .06 & .07 & .02 \\
\hline Remorse & 2.30 & $.41 *$ & $.39^{+}$ & $.50^{*}$ & $.49 *$ \\
\hline Restitution & 1.98 & $.37^{+}$ & .34 & $.38^{+}$ & $.36^{+}$ \\
\hline Reform & 2.28 & $.54 * *$ & $.44 *$ & $.68 * *$ & $.58 * *$ \\
\hline
\end{tabular}

$\mathrm{N}=25 ; * * \mathrm{p}<.01,{ }^{*} \mathrm{p}<.05,{ }^{+} \mathrm{p}<.10$

Because the severity of a transgression influences whether forgiveness occurs (Fincham, Jackson, \& Beach, 2005), these results may be driven by the judge's perception of the severity of the transgression. Therefore we computed a partial correlation between each of the components and the outcomes while holding the effects of severity constant. Table 2 presents these results. As evident in the table, the magnitude of the relationships between the components and forgiveness and trust increases when adjusted for severity. Responsibility still does not predict the outcomes.

\section{DISCUSSION}

The goal of the current research was to test Boyd's (2011) apology component model. Overall it appears that six of the seven proposed apology components predict positive outcomes.

\section{Why are the components effective?}

In order to understand why the components are effective, it is important to consider why apologies work in the first place. Researchers have proposed three potential moderators of the apology-outcome relationship. The various components predict these moderators. Figure 2 demonstrates this relationship. In this model, empathy, altered beliefs, and equity restoration all moderate the relationship between apology and positive outcomes. For example, if an offended party feels empathy for the apologizer, then an apology is more effective than if the offended party did not feel empathy. We suggest here that the specific apology components may predict specific moderators. 


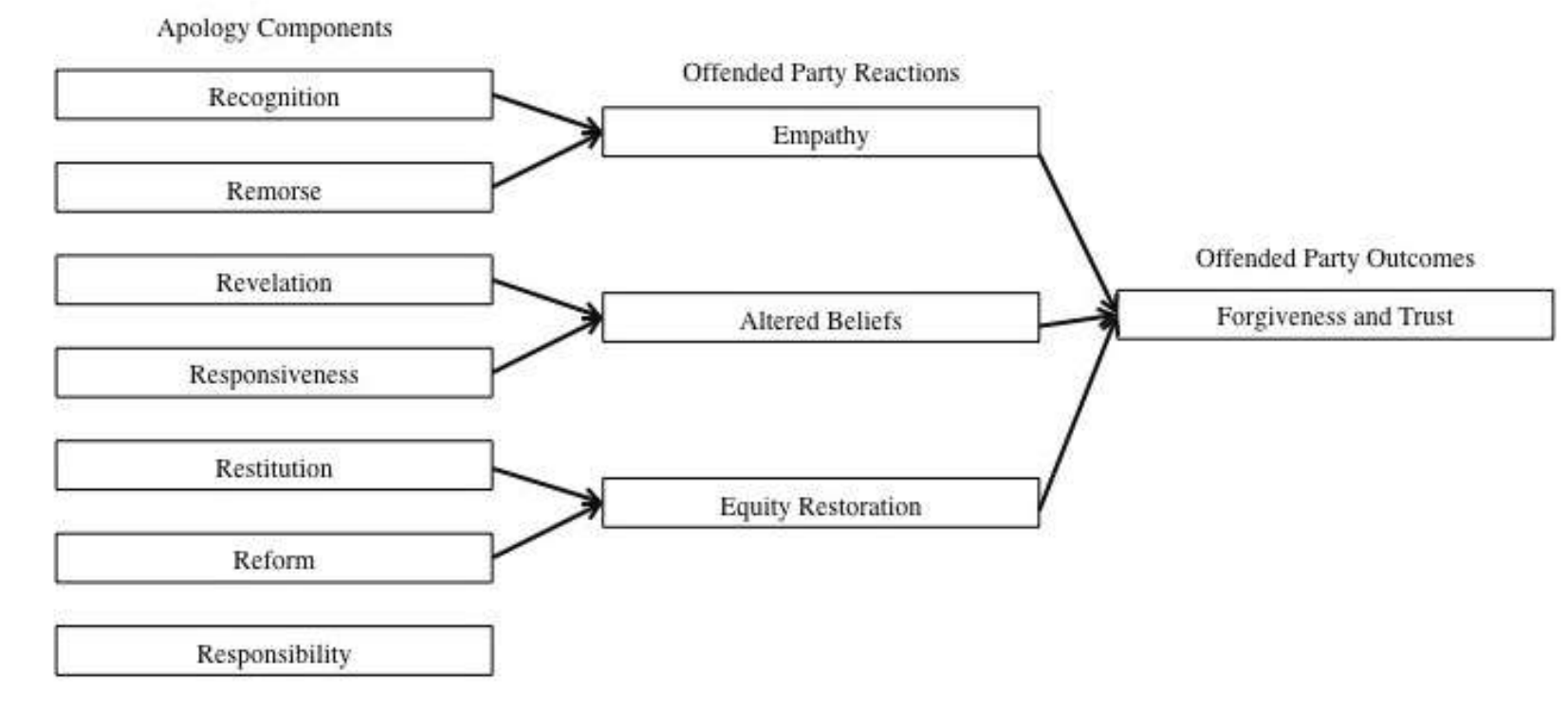

Figure 2: Apology Components, Moderators and Outcomes

The first moderator is offended party empathy for the apologizer. If the offended party becomes aware of how the apologizer is feeling, especially if the apologizer is feeling guilt or remorse, a sympathetic response towards the apologizer may occur and forgiveness results. This is why the components of recognition and remorse may work in eliciting trust and forgiveness among our participants. For example, when JetBlue stated, "Words cannot express how truly sorry we are for the anxiety, frustration, and inconvenience that you, your family, friends, and colleagues experienced" (Neeleman, 2010), our judges may have recognized that JetBlue understood how the offended parties were feeling and felt remorseful about its transgression. The empathy that JetBlue exhibited may have induced sympathy among our judges, thereby inclining them toward trust and forgiveness (e.g., McCullough, Worthington, \& Rachal, 1997).

Researchers have also suggested that forgiveness may occur if an apology can alter the offended parties' belief about the cause of the transgression. Typically after a transgression, offended parties attribute the cause of the transgression to the transgressor's character (Weiner, Graham, Peter, \& Zmuidinas, 1991). For instance, an offended party may say, "The company acted that way because it lacks morals." However, if an apology can convince the offended party that the cause of the transgression was not an inherent character flaw but rather an external factor like the economy or the weather, forgiveness may result. This perception may explain why revelation proved to be the strongest predictor of forgiveness and trust. By acknowledging the transgression, the apologizer and the company demonstrate that they understand rules and norms have been violated. This admittance conveys the message that the transgressor and the company are not immoral and that the misdeed was a chance event. As a result, the apology may override the offended parties' tendency to believe that the company is "bad." Instead offended parties will conclude that the transgression occurred because of the situational context (Weiner, Graham, Peter, \& Zmuidinas, 1991).

This perceptual transference of blame away from the actor may also explain the effectiveness of responsiveness. As Lazare (2005) observes, once a transgression occurs, offended parties begin to form assumptions about the cause of the transgression and the character of the violator. By being responsive and explaining why the transgression occurred, apologizers may be able to abort this process of character denigration. However, if an apology is rendered too late, the damage to the apologizer's reputation may already be done and may be deemed irreversible. Conversely, if an apology is delivered too early, the offended parties may find it insincere because the apologizer has not taken the time to fathom the repercussion for others. As a result, the offended parties hold the apologizer accountable for the transgression. 
The final moderator of the apology-forgiveness relationship is restoration of the offended parties' status. Offended parties experience negative consequences from the transgressions committed against them. If an apology can help offended parties regain their pre-transgression status, it may elicit forgiveness. The action components of restitution and reform may work because they can countervail the consequences suffered by the offended parties (Walster, Berscheid, \& Walster, 1973). Restitution provides either tangible or intangible compensation to the aggrieved. For example, JetBlue offered passengers compensation that could help restore their finances after the cancelled flight. Reform also achieves this goal because it shows victims that both the violation and its aftereffect are unlikely to happen again. If offended parties are satisfied and sense atonement for the transgression, they may become more forgiving (Fagenson \& Cooper, 1987).

\section{Why not responsibility?}

Responsibility was the sole component that failed to be a significant predictor of forgiveness or trust. We propose two explanations for this finding. First, by assuming responsibility and accepting blame, apologizers may fuel the perception that they were a cause rather than a consequence of the bad situation. Transparency presents the transgression in stark features for all to hear and judge. If offended parties believe the apologizer and company are immoral, they may also believe that the apologizer and company will commit the transgression again. Fear of recurrence makes it difficult to forgive and trust.

Second, responsibility may become a contributory factor only if it is followed by action. The mea culpa deluge has dulled the response of offended parties. Responsible avowal is seen as little more than a pro forma prerequisite. Words of themselves carry little import; speech must be realized through an action scenario. The mere assumption of responsibility proves insufficient to induce forgiveness. In the aftermath talk is cheap, but behavior is telling. As one of the transgressors noted, "I know it will be hard to forgive me until you see my sincerity through my actions." Future studies can employ longitudinal designs to determine whether companies uphold their promises over the course of time.

\section{LIMITATIONS AND FUTURE RESEARCH}

One limitation of the current study is the number of apologies used. Twenty-five apologies were chosen so judges could complete the study in a timely fashion. This modest sample does not permit investigation of the impact of alternative variables such as transgression type.

This study specifically focuses on public apologies. The causal dynamics of interpersonal apologies between couples, friends, and family members may prove completely different; the components found to be effective in our study may not pertain to these relationships. In the future researchers should test this possibility.

Another study limitation is our reliance on transcripts rather than witnessed apologies. By utilizing transcripts, we were unable to ascertain the role of nonverbal cues such as tonality and facial expression. Future researchers may wish to examine the salience of these cues in apologizers' quest for forgiveness.

In conclusion, our study demonstrates that various apology components play a significant role in eliciting forgiveness and trust. However, responsibility appears to be ineffective. As they frame apologies for their transgressions, CEOs may wish to take our results into account.

\section{AUTHOR INFORMATION}

Krista M. Hill, Ph.D. candidate at Northeastern University, has three primary research interests: 1) the effectiveness of apologies, 2) the ability to judge the internal states of others, and 3) meta-analysis. Her research has been presented at several national conferences including the International Business and Economics Research Conference of the Clute Institute, the annual meeting of the Society for Personality and Social Psychology, and the New England Meeting for Teachers of Psychology.

David P. Boyd, D.Phil., is a Professor of Management and Organizational Development at Northeastern University's D'Amore-McKim Business School where he served as dean for seven years. He has published over 
seventy articles in the area of organizational psychology and entrepreneurial leadership. He holds a BA from Harvard University and a D. Phil. from Oxford University, England. E-mail: d.boyd@ neu.edu (Corresponding author)

\section{REFERENCES}

1. $\quad$ Boyd, D.P. (2011) Art and artifice in public apologies. Journal of Business Ethics, 104 (3), 299-309. DOI: 10.1007/s10551-011-0915-9

2. Cremer, van Dijk, \& Pillutla (2010). Explaining unfair offers in ultimatum games and their effects on trust: An experimental approach. Business Ethics Quarterly, 20(1), 107-126.

3. Eaton, J., Struthers, C., Shomrony, A., \& Santelli, A. G. (2007). When apologies fail: The moderating effect of implicit and explicit self-esteem on apology and forgiveness. Self And Identity, 6(2-3), 209-222. doi:10.1080/15298860601118819

4. Fagenson, E. A., \& Cooper, J. (1987). When push comes to power: A test of power restoration theory's explanation for aggressive conflict escalation. Basic and Applied Social Psychology, 8, 273-293.

5. Fehr, R., Gelfand, M. J., \& Nag, M. (2010). The road to forgiveness: A meta-analytic synthesis of its situational and dispositional correlates. Psychological Bulletin, 136(5), 894-914. doi:10.1037/a0019993

6. Fincham, F. D., Jackson, H., \& Beach, S. H. (2005). Transgression Severity and Forgiveness: Different Moderators for Objective and Subjective Severity. Journal Of Social And Clinical Psychology, 24(6), 860875. doi:10.1521/jscp.2005.24.6.860

7. Goei, R., Roberto, A., Meyer, G., \& Carlyle, K. (2007). The effects of favor and apology on compliance. Communication Research, 34(6), 575-595. doi:10.1177/0093650207307896

8. Hareli, S., Shomrat, N., \& Biger, N. (2005). The role of emotions in employees' explanations for failure in the workplace. Journal Of Managerial Psychology, 20(8), 663-680. doi:10.1108/02683940510631435

9. Howley, M.J. (2009). The use of apology in health care. Journal of Medical Marketing, 9(4), 279-289. doi: $10.1057 / \mathrm{jmm} .2009 .30$

10. Lazare, A. On Apology. (2005). Oxford, England: Oxford University Press Inc.

11. Liao, H. (2007). Do it right this time: The role of employee service recovery performance in customerperceived justice and customer loyalty after service failures. Journal of Applied Psychology, 92(2), 475489. doi:10.1037/0021-9010.92.2.475

12. Lyon, L., \& Cameron, G. T. (2004). A Relational Approach Examining the Interplay of Prior Reputation and Immediate Response to a Crisis. Journal Of Public Relations Research, 16(3), 213-241. doi:10.1207/s1532754xjprr1603_1

13. Mason, A. (2011, February 10). One last post on the superbowl (Web log post). Retrieved from https://blog.groupon.com/cities/one-last-post-on-the-super-bowl/

14. McCullough, M. E., Worthington, E.R., \& Rachal, K. C. (1997). Interpersonal forgiving in close relationships. Journal Of Personality And Social Psychology, 73(2), 321-336. doi:10.1037/00223514.73.2.321

15. Neeleman, D. (2010, February 19). (Web log post) Retrieved from http://www.jetblue.com/about/ourcompany/apology/index.html

16. Walster, E., Berscheid, E., \& Walster, G. W. (1973). New directions in equity research. Journal of Personality and Social Psychology, 25, 151-176.

17. Weiner, B., Graham, S., Peter, O., \& Zmuidinas, M. (1991). Public confession and forgiveness. Journal of Personality, 59, 281-312. doi: 10.1111/j.1467-6494.1991.tb00777.x

18. Xie, Y., \& Peng, S. (2009). How to repair customer trust after negative publicity: The roles of competence, integrity, benevolence, and forgiveness. Psychology \& Marketing, 26(7), 572-589. doi:10.1002/mar.20289

19. Zechmeister, J. S., Garcia, S., Romero, C., \& Vas, S. N. (2004). Don't Apologize Unless You Mean It: A Laboratory Investigation of Forgiveness And Retaliation. Journal Of Social And Clinical Psychology, 23(4), 532-564. doi:10.1521/jscp.23.4.532.40309 